\title{
Integrated Tool for High-Feed Turning
}

Karol Vasilko

Faculty of Manufacturing Technology, Technical University of Košice, 08001 Prešov, Bayerova 1, SR, E-mail: karol.vasilko@tuke.sk

Machining, mainly turning, si characterised by the highest labour input among the technological methods. This leads to the conditin when, for instance, in line production at hammering power press, which produces forginngs in the stroke of 1 second, tens of lathes follow and their gradual turning with the stroke of tens of seconds up to minutes. Whole history of material machining has been lead with the effort to shorten machining time by the improvement of cutting materials, tool geometry, integration of machining The article based on the method integrates roughing and finishing into one operation and ensures high quality of machined workpiece surface.

Keywords: Turning, Tool geometry, Cutting speed, Surface roughness

\section{Introduction}

The attempts to shorten machine time for turning face the law between the machine time and cutting conditions. One of the ways how to solve it is to increase the cutting speed. This, however, may be limited due to concurrent shortening of cutting tool durability according to a wellknown Taylor formula. $T=\frac{C_{\mathrm{T}}}{v^{\mathrm{m}}}, \min [1],[2],[7]$. Another way is the so-called high-feed turning [5], [12]. This requires adjustment of the geometry of the cutting wedge and mainly avoidance to use a tool with a rounded tip. The solutions are based on creating sections of the cutting edge parallel with the tool feed. This solutions are limited by intense tool friction against the workpiece transition area. The presented solution is based on the use of side cutting edge to finish the workpiece surface. This is the way how an integrated tool for concurrent roughing and finishing in one feed is created.

\section{Tool principle}

The main cutting edge is located under the following angles: $\lambda_{\mathrm{n}}=0^{0} ; \boldsymbol{x}_{\mathrm{r}}=90^{\circ}$. The side cutting edge is located skew to the workpiece axis, e.g. under angle $\lambda_{s}^{\prime}=45^{0}$ in accordance with Fig.l [13].

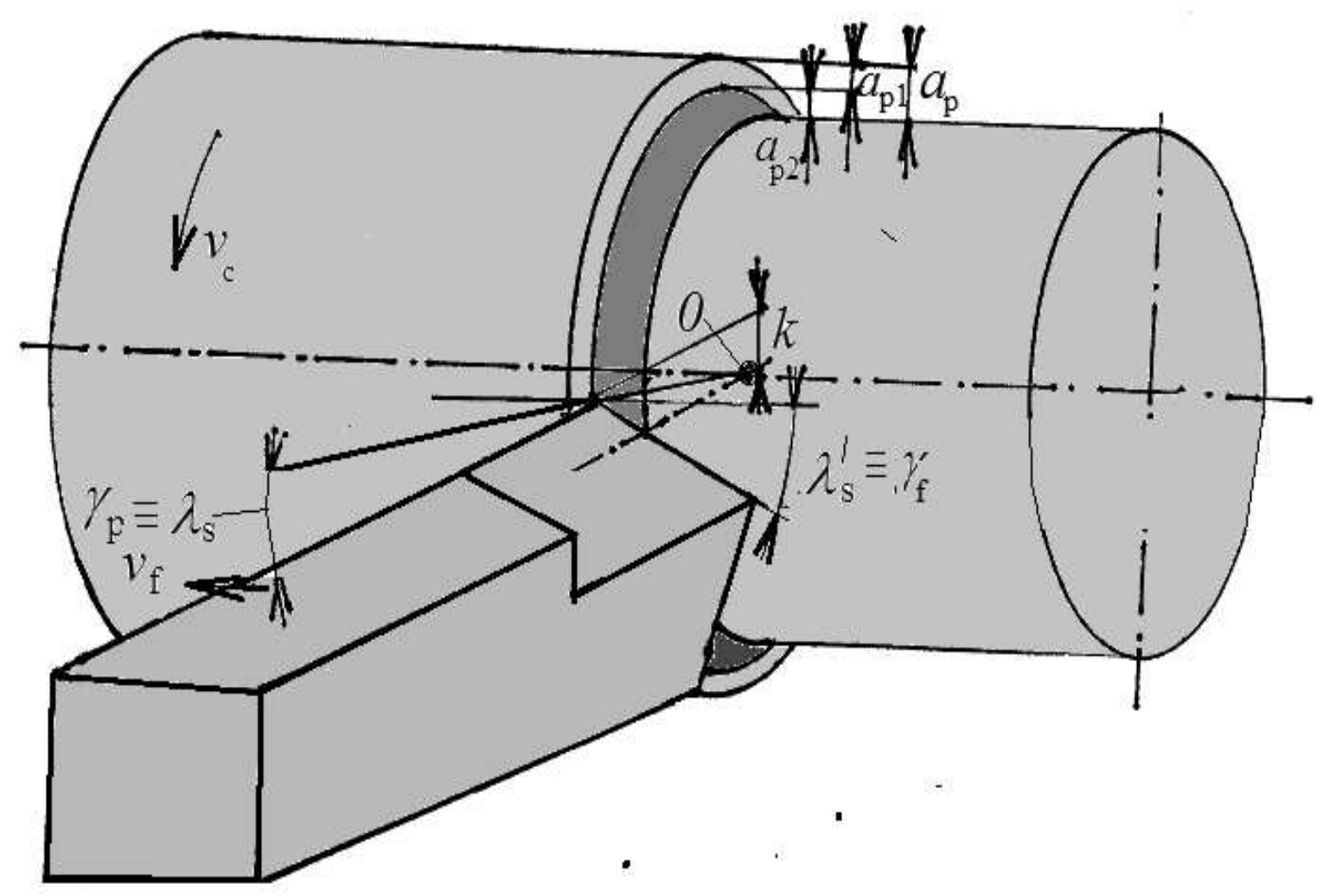

Fig. 1 Interaction of integrated tool with workpiece. 
During turning, the tool tip is set to value $k$ above the workpiece axis. Then the main cutting edge is cutting off the cut depth $a_{\mathrm{p} 1}$, which can be defined as roughing. The side cutting edge is taking off the finishing cut depth $a_{\mathrm{p} 2}$. The ratio $\frac{a_{\mathrm{p} 1}}{a_{\mathrm{p} 2}}$ depends on the tool adjustment $k$.

If $k=0$ tool is working as a classical roughing knife with tip radius and geometry: $x_{\mathrm{r}}=90^{0} ; x_{r}^{\prime}=0^{0}$.

The machined surface uneveness height can be expressed by a classical formula [3], [12]:

$$
R z=\frac{f^{2}}{8 . r_{\varepsilon}}, \mathrm{mm}
$$

When it is exceeded by value $k>a_{\mathrm{p}}$, only side cutting edge would be in feed with the workpiece and the tool would work as a roughing knife with one linear cutting edge, skew to the workpiece axis.

Another peculiarity of the tool is the angle oneness:

$$
\lambda_{s} \equiv \gamma_{\mathrm{p}}
$$

and for $\varkappa_{\mathrm{r}}=90^{\circ}$ and $\gamma_{\mathrm{p}}=0$, also

$$
\lambda_{s \mathrm{~s}} \equiv \gamma_{\mathrm{f}}
$$

\section{Analysis of geometrical relations}

After setting the tool, the location of the side cutting edge against the workpiece is shown in Fig. 2.

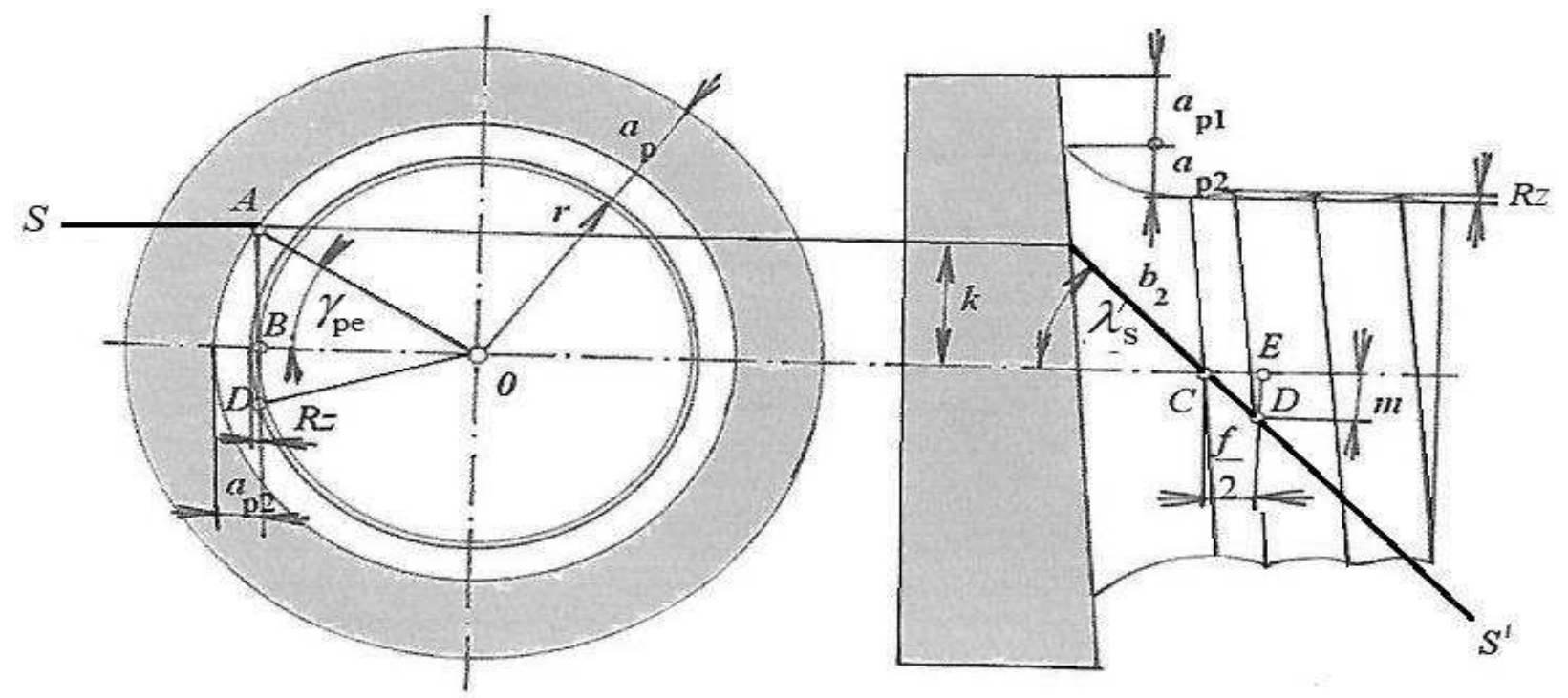

Fig. 2 Scheme to determine the uneveness height of machined surface

If, for simplicity sake, the following is selected $\varkappa_{\mathrm{r}}=$ $90^{\circ}$, a formula for the highest uneveness height of machined surface can be derived:

As follows:

$$
\operatorname{tg} \lambda_{s}^{\prime}=\frac{2 . m}{f}
$$

From which:

$$
m=\frac{f}{2} \cdot \operatorname{tg} \lambda_{s_{\mathrm{s}}^{\prime}} \cdot
$$

Also:

$$
\begin{gathered}
m^{2}=(r+R z)^{2}-r^{2} . \\
\frac{f^{2}}{4} \cdot \operatorname{tg} \lambda_{s}=\left(r+R z^{2}\right)-r^{2} \\
\frac{f^{2}}{4} \cdot \operatorname{tg} \lambda_{s}^{2}=r^{2}+2 \cdot r \cdot R z+R_{z}^{2}-r^{2}
\end{gathered}
$$

Because $R z^{2}$ has a small value, it can be neglected and after shortening $r^{2}$, the following can be derived:

$$
R z=\frac{f^{2} \cdot \operatorname{tg} \lambda_{s}}{8 r}=\frac{f^{2} \cdot \operatorname{tg} \lambda_{s}}{4 \cdot D}, \mathrm{~mm}
$$

In the formula, two new parameters appear, $\lambda_{\mathrm{s}}$ and $D$. By increasing the angle of side cutting edge incline, $R z$ is growing, and it decreases with the increase of the workpiece diameter.

If the following is selected for simplicity reasons: $\lambda_{s}=45^{2}$, a simple formula appears:

$$
R z=\frac{f^{2}}{8 . r}, \mathrm{~mm}
$$

After substitution into both formulas, the relation (5) gives much smaller values of $R z$, because $r » r_{\varepsilon}$.

The tool also possesses some peculiarities as for the creation of working angles. E.g. working angle of the incline of the main cutting edge in point $A$ can be defined as 
follows from Fig. 2:

$$
\lambda_{\mathrm{se}}=\gamma_{\mathrm{pe}}=\operatorname{arctg} \frac{k}{r+a_{\mathrm{p} 1}}
$$

and it decreases to zero from point $C$.

A set of experimental tests with a tool with different geometry. In Fig. 3 there is an experimental dependence of the highest uneveness height of the profile on the feed when turning steel by a knife from Fig. 1 with tip radius $r_{\varepsilon}$ located in workpiece axis and a set of tools with different angles $\lambda_{s}^{\prime}$, set by $k=1 \mathrm{~mm}$, at workpiece diameter $70 \mathrm{~mm}$

In Fig. 3 there is a set of experimental dependences $R a=\mathrm{f}(f)$.

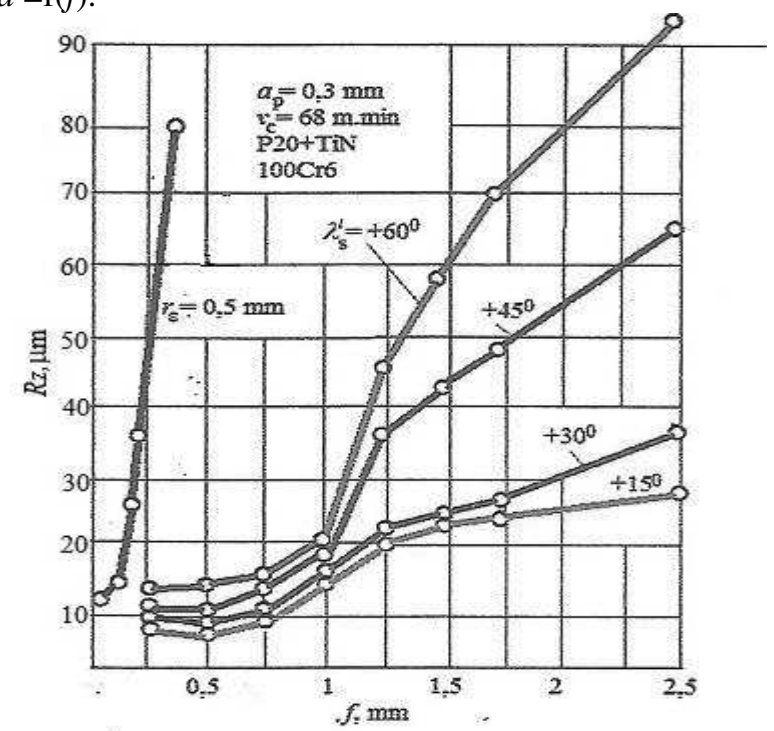

Fig. 3 Experimental dependences $R z-f . D=70 \mathrm{~mm}, k=$ $1 \mathrm{~mm}$.

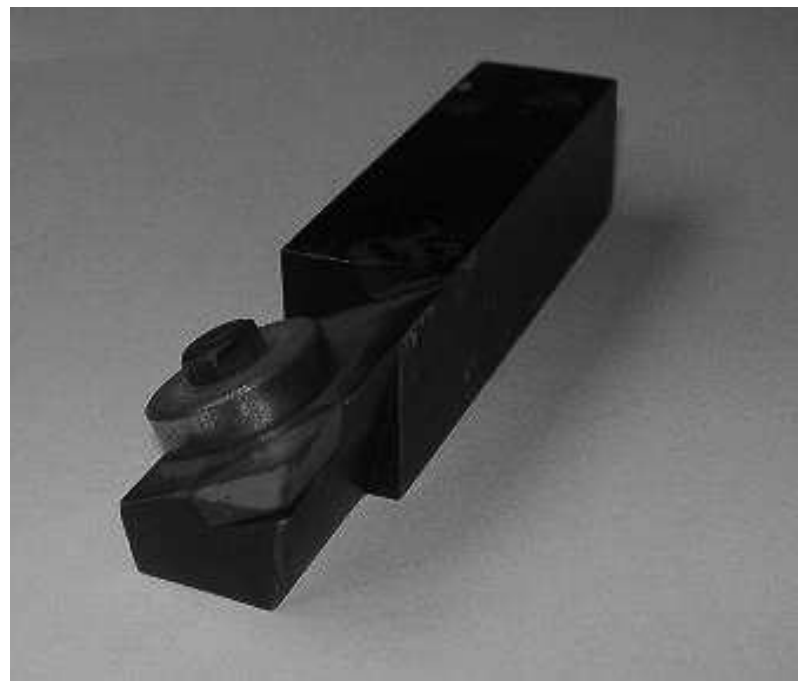

Fig. 4 View of tool

In comparison with the tool located in the workpiece axis, after setting the tool, there has occured an immense improvement of the quality of machined surface for all used $\lambda_{s}^{\prime}$

At the same time, the values $R z$ are logically smaller than at smaller angles $\lambda_{s}^{\prime}$.

In Fig. 4 there is a view of an experimental tool with the following geometry: $x_{\mathrm{r}}=90^{\circ} ; \lambda_{s}^{\prime}=45^{\circ}$.

\section{Sample of effective tool application}

As an effective tool application, wood turning can be selected. Wood is a material with polymorphic structure [4],[8]. The process of turning works as a split-creating mechanism, which has a negative effect on the quality of machined surface. An increased quality can realistically be supposed when the tool is used because when the surface is being finished by a side cutting edge, there occurs a free cut, similarly to planing or peeling. For experimental verification, typical species of used wood.

In Fig. 5 there is a method of setting the tool against the workpiece.

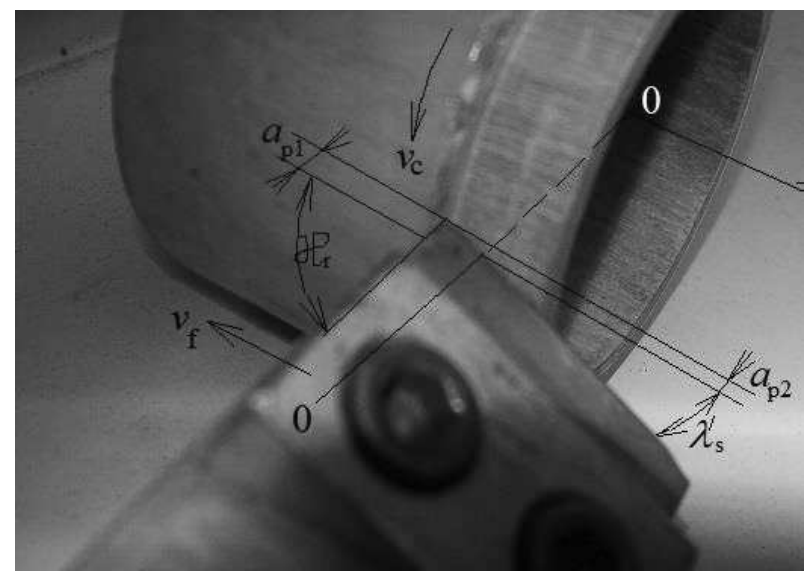

a)

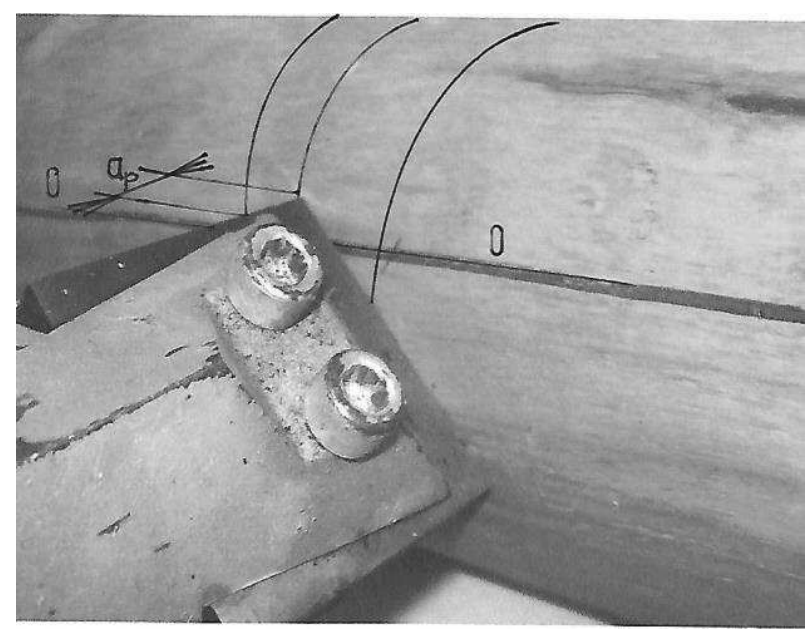

b)

Fig. 5 Setting of the tool for turning a wooden roll with diameter $70 \mathrm{~mm}$ (a) and round log with diameter $300 \mathrm{~mm}$ (b). 0-0-position of workpiece axis

In Fig. 6 there is experimental course of dependences $R z=\mathrm{f}\left(v_{\mathrm{c}}\right)$, obtained during hornbeam round log turning. 


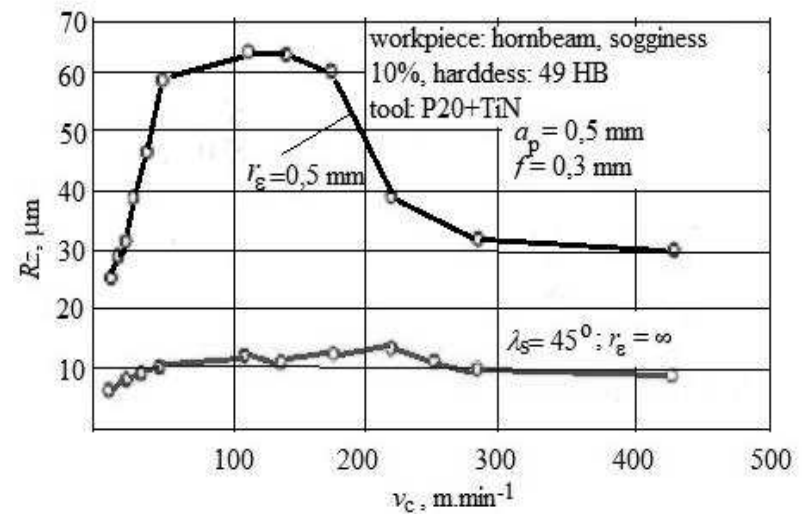

Fig. 6 Experimental diagramme of dependence $R z=$ $f\left(v_{c}\right)$ after turning with a tool with tip radius and an integrated tool.

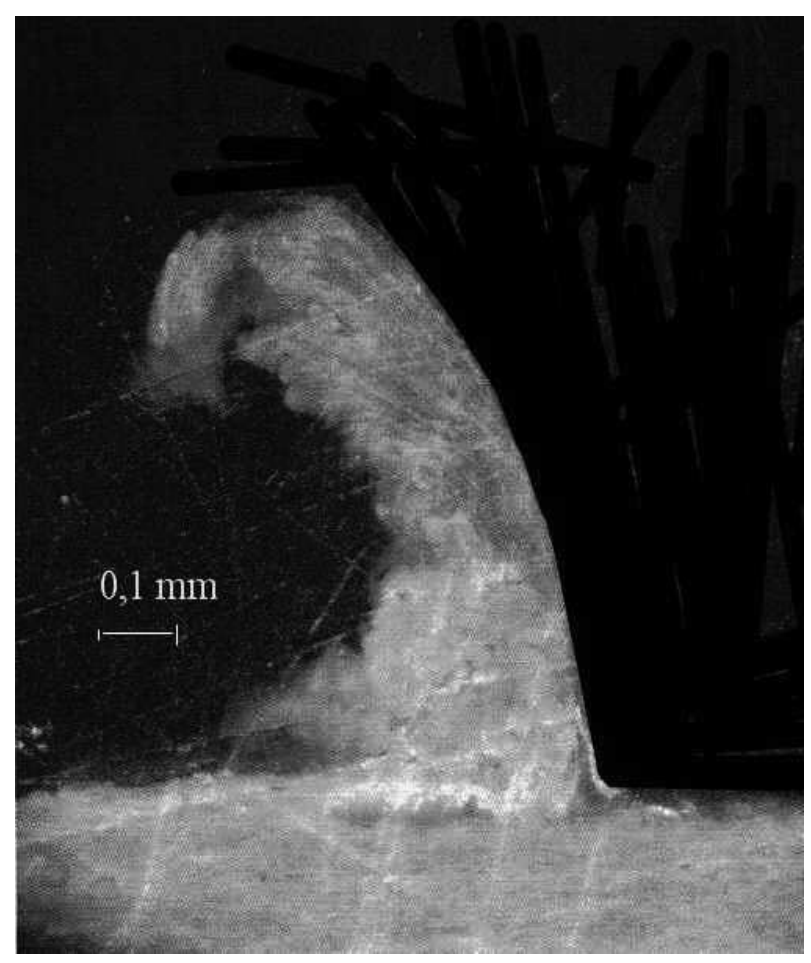

Fig. 7 Photography of thin section of chip creation at cutting speed $v_{\mathrm{c}}=250 \mathrm{~m} \cdot \mathrm{min}^{-1}$

Certain important facts can be deduced from the diagramme. When a classical roughening knife is used, the value of $R z$ greatly depends on cutting speed. It is wellknown from actual practice that wood requires high cutting speeds. In this case, the unfavourable area of cutting speeds is $v_{c}\langle 30 ; 220\rangle \mathrm{m} \cdot \mathrm{min}^{-1}$.

$R z$ practically does not depend on cutting speed when it is turned by an integrated tool. Cutting speeds used for turning steel can therefore be used as well.

A chip leaving the tool with the tip radius is segmented in whole range of cutting speeds. For the integrated tool, a fluent chip leaves the side cutting edge, similarly to planing. A thin section of the zone of chip creation after stopping the turning process has been made. A view of the thin cut sample is shown in Fig. 7.

It can be seen that the chip is fluent, with marks of plastic deformation, similarly to steel. The moment of chip capture corresponds with turning in the direction of the ring.

In Fig. 8 there is a photography of the thin section for the case of turning in skew direction to the ring. The course of chip creation is identical.

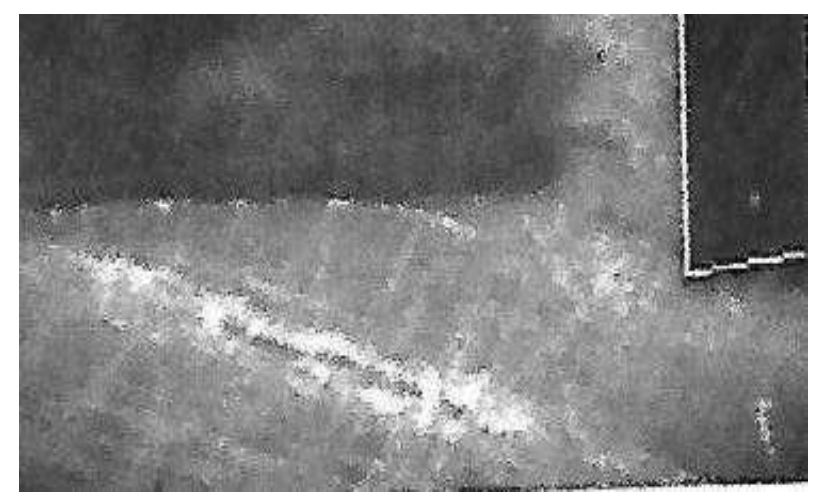

Fig. 8 Photography of thin section of chip creation zone when turning in skew direction to the ring In Fig. 9 there is a similar diagramme obtained when oakwood has been turned.

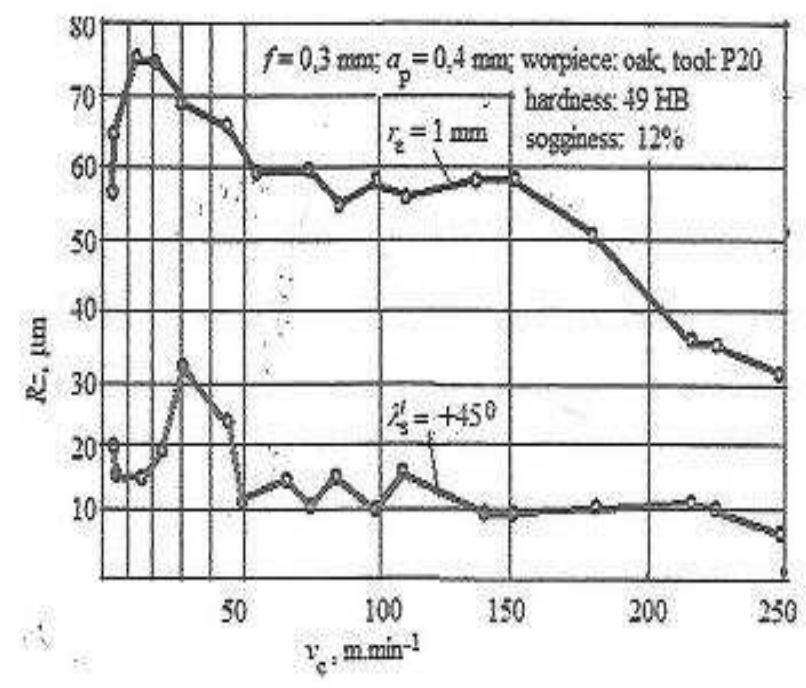

Fig. 9 Experimental diagramme of dependence $R z=$ $f\left(v_{c}\right)$, corresponding with turning oakwood.

A change of $R z$ for the increase of $v_{\mathrm{c}}$ is even more significant than at Fig. 6. For the integrated tool the course is similar, with the exception of cutting speed up to $50 \mathrm{~m} \cdot \mathrm{min}^{-1}$.

In Fig. 10 there is an example of a record of microgeometry of machined surface by a classical and integrated tool at the cutting speed $20 \mathrm{~m} \cdot \mathrm{min}^{-1}$. As it can be seen, apart from considerably smaller values of $R z$ there is also higher material portion of the surface. 


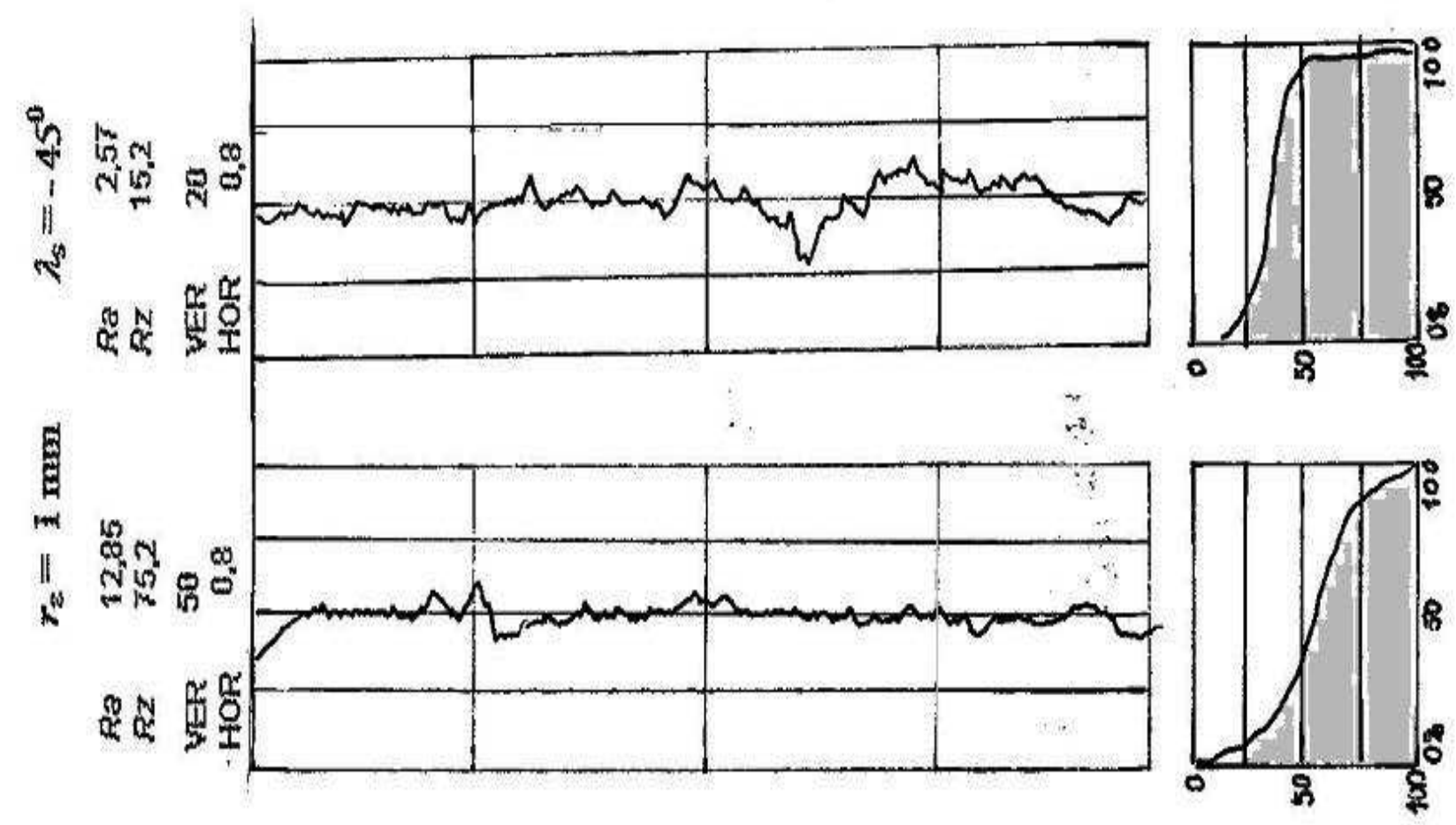

Fig. 10 Recording of microgeometry of machined surfaces by classical and integrated tool, corresponding to cutting speed $20 \mathrm{~m} . \mathrm{min}^{-1}$

Besides a considerable decrease of $R z$ the recording also documents much higher material portion of machined surface.Hazelwood has been turned as an example of soft woods. The result is shown in Fig. 11.

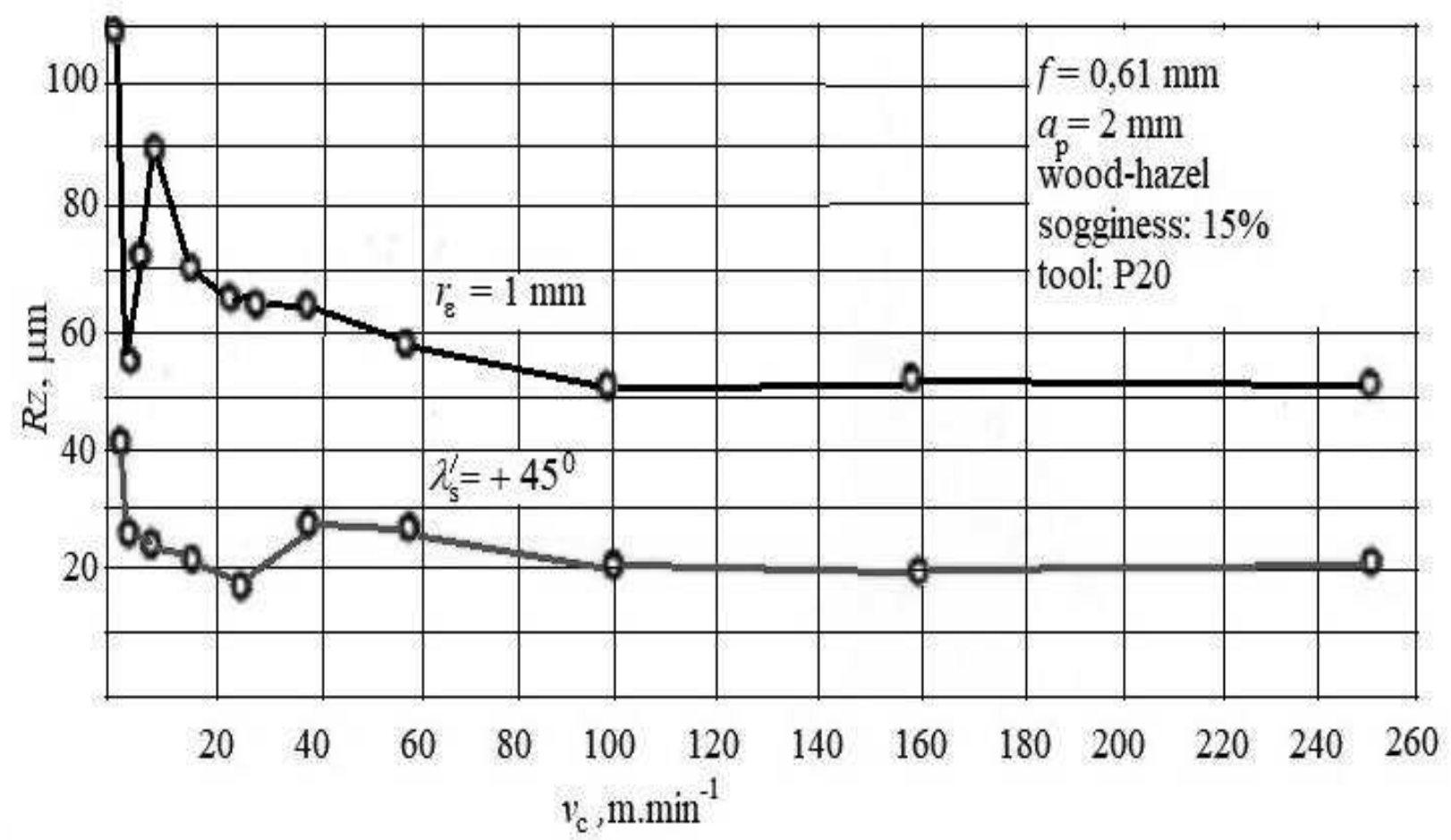

Fig. 11 Experimental diagramme of dependence of $R z-v_{c}$, obtained by turning hazelwood. 
In comparison with previous cases, for the tool with tool radius, there is a more fluent decrease of $\mathrm{Rz}$ with cutting speed, except the areas of $\mathrm{v}_{\mathrm{c}}$ up to $20 \mathrm{~m} \cdot \mathrm{min}^{-1}$.

\section{Conclusion}

The paper indicates a possibility to join roughing and finishing the surface in one feed rationally. This requires to develop tools with adjusted geometry, which leads to the integration of the side cutting edge into material reduction. Besides turning common construction materials, this application seems to be suitable to turn non-homogenous materials as well, for instance composites. From the viewpoint of practice, mainly quality of machined surfaces of wokrpieces appears to be interesting.

\section{References}

[1] DE CHIFFRE, I.: Metal cutting. Mechanics and aopplications. Lydgby, Technical University of Denmark, 1990.

[2] GRZESIK, W.: Podstavy skrawania materialow konstrukcyjnych.Warszawa, 2010, 52 s., ISBN 978-83-204-3668-6,

[3] HOLEŠOVSKÝ,F., HRALA, M., NOVÁK, M.: Ground Surface - Quality and its Loading Capacity. Manufacturing Technology, Vol. 3, 2013, pp. 26-32, ISBN 1213-2489.

[4] JERSAK, J et al: The integrity of th Surface after Milling of uenched Bearing Stell Manufacturing
Technology, 2017, No. 4, pp.13-20, ISSN 12132489.

[5] KALPAKJIAN, S.: Manufacturing Engineering and Technology. New York: EddisonWesley Publishing Company, 1989, 1199 p.

[6] KOTĚŠOVEC, V.: Ortogonální frézováni dřeva, 25/1981, VVUD Praha

[7] KOVAČ, P., MIKILIČ,D.: Rezanje metala. Univerzitet v Novom Sadu, 1998, 300 s. ISBN 86899-40015-1

[8] LISIČAN, J.: Teória a technikaspracovania dreva. Zvolen, MATCENTRUM, $1996626 \mathrm{~s}$.

[9] NEMEC, E.: K filozófii nášho odvetvia. Drevo 48, 1993, č.6, s.

[10] NOVÁK, M.: Surface with high precision of roughness after grinding. Manufacturing Technology, Vol 12, No. 12, pp.66-70, ISSN 12132489.

[11] POŽGAJ, A. t al.: Štruktúra a vlastnosti dreva. Príroda a spoločnost', 1997, 486 s.

[12] TURKOVICH, B., F.: A contribution to the theory of metal cutting. Proc. Int. Conf.Prod. Eng. Tokio, 1974, Part 1, s. 505-508.

[13] ÚRAD PRIEMYSELNÉHO VLASTNÍCTVA SR. Nástroj na sústruženie. Patent SR, č.: 280127., pôvodca: Karol Vasilko 